\title{
How to improve innovation in sustainable tourism? Five lessons learned from the Austrian Alps
}

Jasper Hessel Heslinga, Hans Hillebrand and Tanja Emonts

\begin{abstract}
Purpose - The purpose of this paper is to propose lessons learned on how innovation can help facilitate sustainable tourism in regions. Sustainable tourism is a promising concept for a resilient future of tourism destinations, however, its practical implication remains a challenge.

Design/methodology/approach - To gain these practical lessons on innovation, a so-called "inspirational journey" was organized. An interdisciplinary group of experts went to the Austrian Alps and many local initiatives and innovative ideas were presented.

Findings - As a result of this journey, the authors advocate five lessons that can help improve sustainable tourism in the future.

Practical implications - Being a source of inspiration for policy-makers and planners, these lessons can be applied to other regions.
\end{abstract}

Originality/value - The added value of this viewpoint paper is that it provides practical examples on how innovation can help improve sustainable tourism in the future.

Keywords Innovation, Seasonality

Paper type Viewpoint

\section{Introduction}

The purpose of this viewpoint paper is to propose lessons learned on how innovation can help facilitate sustainable tourism in a region. Sustainable tourism can assist in steering toward a resilient future of tourism destinations (Hartman, 2016, 2018; Heslinga, 2018). Tourism destinations are facing many future socio-economic and environmental changes to which they constantly need to adapt to (Davidson, 2010; Lew, 2014). Resilience thinking has recently gained importance as a concept to understand how to deal with these changes (Biggs, 2011; Espiner and Becken, 2014; Lew, 2014; Luthe and Wyss, 2014; Heslinga et al., 2019). Resilience thinking can be helpful in helping decision-makers process more-informed future decisions for managing tourism destination that are future proof.

For decision-makers to make better future decisions, sustainable tourism is a promising concept that has been around for quite some years now and still receives much attention. For example, in 2017, the International Year of Sustainable Tourism was celebrated. Over the years, much work has been done conceptually, but it remains difficult to have an all-encompassing definition of sustainable tourism. Nevertheless, we think that, expressed simply, sustainable tourism can be defined as:

Tourism that takes full account of its current and future economic, social and environmental impacts, addressing the needs of visitors, the industry, the environment and host communities (UNWTO, 2005).

Apart from definition issues, we observe that the application of the concept in practice remains a challenge (Heslinga et al., 2017; Lew, 2014). Therefore, in this viewpoint paper, we contribute to the academic debate by specifically drawing attention to concrete practical examples of innovation in sustainable tourism. We argue that innovation can play an important role in making
Jasper Hessel Heslinga is based at European Tourism Futures Institute (ETFI), NHL Stenden University of Applied Sciences, Leeuwarden, The Netherlands and Centre of Expertise Leisure, Tourism and Hospitality (CELTH), Breda, The Netherlands.

Hans Hillebrand is based at Stichting Innovatie Recreatie en Ruimte (STIRR), Zeist, The Netherlands.

Tanja Emonts is based at Emonts Advies, Den Hoorn, The Netherlands.

Received 20 September 2018 Revised 12 January 2019

7 March 2019

9 March 2019

Accepted 10 March 2019

C Jasper Hessel Heslinga, Hans Hillebrand and

Tanja Emonts. Published in Journal of Tourism Futures. Published by Emerald Publishing Limited. This article is published under the Creative Commons Attribution (CC BY 4.0) licence. Anyone may reproduce, distribute, translate and create derivative works of this article (for both commercial and non-commercial purposes), subject to full attribution to the original publication and authors. The full terms of this licence may be seen at http://creativecommons.org/ licences/by/4.0/legalcode 
sustainable tourism work, because creativity, a problem-solving approach and new ways of thinking (Moscardo, 2008; Hjalager, 2010) can offer alternative solutions. In our viewpoint paper, we consider innovation to be defined in the broad sense; moving beyond solely product innovation and include process innovation, management innovation and institutional innovation (Hjalager, 1997).

To address this gap of practical examples of innovation, we advocate five lessons that can help improve sustainable tourism, which are the result of a so-called "Inspiration journey" organized by STIRR. During this journey, an interdisciplinary group of experts from the Netherlands, consisting of tourism entrepreneurs, nature protectors, government representatives and scientists, visited the Austrian Alps where many local initiatives and innovative ideas were presented. By presenting these lessons from practice we hope to inspire planners and policy-makers elsewhere in the world to improve the attempts for innovation in sustainable tourism in the future.

\section{A journey with an interdisciplinary group}

The lessons are based on insights gathered during a journey with an interdisciplinary group of experts involved in sustainable tourism. The Dutch foundation STIRR (In Dutch: Stichting Innovatie Recreatie en Ruimte) is an initiative of a number of front runner leisure entrepreneurs and acts as a driver of initiatives on the cutting edge of tourism and spatial planning. Its ambition is to make recreation and tourism (the hospitality sector) a valued partner in regional development. STIRR does this by supporting and stimulating (strategic) innovations in practice (STIRR, 2018).

One of the initiatives is regularly organizing a journey for an interdisciplinary group of experts involved in tourism. The underlying thought is for them to become inspired and take back home valuable knowledge that can be applied in the Netherlands. Since sustainable tourism is about balancing the current and future economic, social and environmental impacts, we believe an approach that cross-cuts disciplines is fundamental. The group of experts that attended the journey to the Austrian Alps (more about the case below) was selected using the Triple Helix model for innovation where government, industry and education/research were all present.

A total of 11 participants attended the journey (June 20-23, 2018) and consisted of two mayors (one from an urban and another from a rural municipality), a representative from the National Forest Agency, a program manager for the development of a national park, a program manager from the center of expertise on nature and environment, the director development of a large holiday-homes company, the director of a construction company, the director of a management and exploitation organization of recreation areas, a program manager from the center of expertise in leisure, tourism and hospitality and finally two representatives of STIRR.

\section{Why to the Austrian Alps?}

The Alps, and Austria specifically, is a very relevant case to assess innovation in sustainable tourism, because these areas are known as strong supporters of sustainable tourism. Compared to many other places in the world, the places that were visited are quite far with applying the concept of sustainable tourism into practice. In the area of tourism mobility and sustainability the Alpine Pearls initiative is a renowned example, in which the Austrian municipality of Werfenweng is a front runner. Tourism destination Ellmau is an inspiring example that has been very successful in extending the tourism season. Ellmau lies at a height of $800 \mathrm{~m}$ (see Plate 1 for an impression), which means snow is not guaranteed in winter. Government and tourism entrepreneurs joined forces to develop a varied year-round tourism product, such as theme and adventure parks. They also strongly cooperate with other sectors such as the music and film industry.

Both tourism destinations are relevant case and interesting case, because the regional cooperation between public and private (tourism) organizations is strongly developed, which contributes to innovation. Furthermore Austrian tourism regions have a very interesting tourism financing system to further enhance tourism facilities. These aspects make both destinations attractive to visit. 


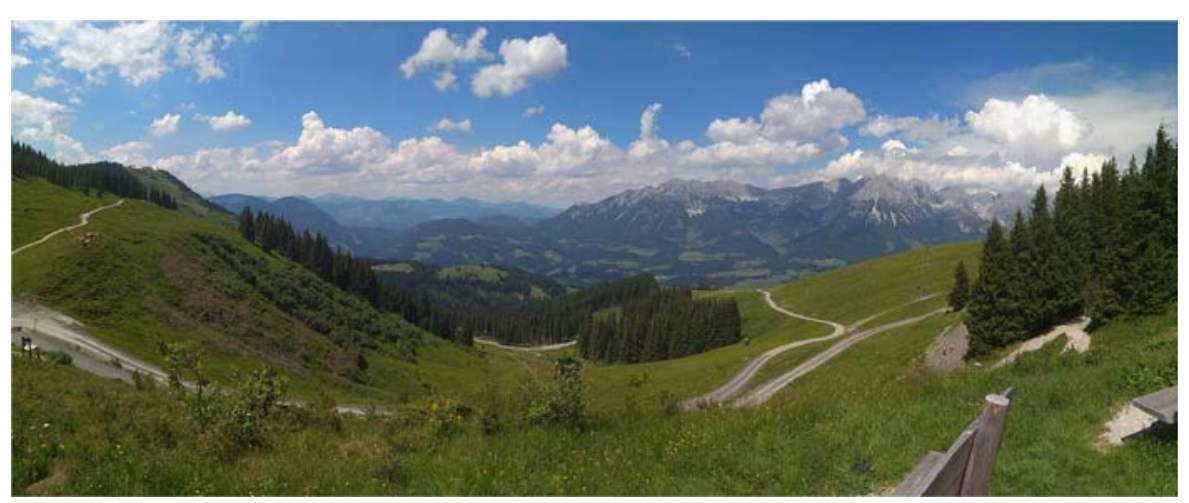

Source: Authors (2018)

The Alpine Pearls is an association of 25 municipalities in the six Alpine countries (Alpine Pearls, 2018). It was established in 2006. The association was the result of two successive EU projects. Both of these projects originated in an initiative by the Austrian Ministry of Agriculture, Forestry, Environment and Water Management. The idea behind the Alpine Pearls was to create innovative tourist packages that protect the environment. The results of these EU projects were implemented by creating the transnational umbrella organization Alpine Pearls for the entire Alpine region. Participating municipalities need to abide to strict environmental quality criteria. Of the five Austrian Pearls, Werfenweng is most advanced in offering sustainable transportation at its destination with a special tourist mobility card that enables tourists to use electrical transportation for free. Sustainable energy is also high on the agenda: the destination generates electricity from its own biomass facility and solar power plant.

\section{Five lessons learned from the Austrian Alps}

\subsection{Vision and leadership is needed}

We observed that a clear vision for the future is needed to be able to successfully develop sustainable tourism at a destination. That vision must be formulated in such a way that it is attractive for a broad range of stakeholders. It is also important that, when developing the vision, broad involvement of stakeholders is organized to prevent people or groups feeling passed. Leadership, in the sense of direction and indicating ambition can certainly improve the quality of the vision.

What strikes in Austria is the attitude toward tourism. It is obvious that tourism is considered not to be an end goal in itself, but seen as a means to maintain the quality of life in the region. This attitude is a change in mind-set which could more and more change the way tourism is considered in the future:

Tourism is here seen a means to increase quality of life, not an end goals in itself (Mayor of a Dutch rural municipality, 2018).

We were told that the landscape is the major carrier of the tourist product. Developments that do not fit into the landscape and do not contribute to the quality of life are repelled. The overall picture in the region shows quality in every aspect and also the hospitality from the population contributes to this feeling.

\subsection{Close collaboration between stakeholders is crucial}

One of the most important success factors of sustainable tourism in Ellmau (and in Tyrol in general) lies a bit deeper, and concerns the involvement of the community and the great 
organizational interdependence. The community is strongly involved in developments or in many cases even (co-) owner. Because of this, there is the realization that for the community itself there is also something to be gained from tourism and therefore there is public support. In addition, the local population is also represented in all kinds of advisory bodies, such as the Wilder Kaiser Tourism Association, of which Ellmau is a part:

The unambiguous vision and passion on local and regional level, supported by the public and private sector, is inspiring (Mayor of a Dutch city, 2018).

A main explanation of the large organizational interwovenness is that 90 percent of the companies are family businesses. However, the continued existence of these businesses is currently under pressure and this is a potential threat in the future. In addition to the fact that the percentage of family businesses is decreasing, it is becoming increasingly difficult to recruit qualified staff in the future and companies are often dependent on people from abroad.

\subsection{The tourism financing system needs to be transparent and fair}

Since 1927, Tirol has an elaborated tax system to improve tourism development. The general idea is that the revenues are actually reinvested in the development of tourism and the maintenance of the environment. Interestingly, all businesses in the region pay for tourism development. Also those that are not directly part of the tourism sector, but do benefit from it indirectly. This system makes financing of tourism in the destination more transparent and fair.

The tax systems consists of two parts: a tourist tax; and a so-called Pflichtbeitrag, being an obligatory contribution. The tourist tax is an amount that, like in many countries, is paid by the overnight tourist. The difference is that the money remains at the local "Tourism Association." The Pflichtbeitrag is an additional tax system that covers all companies in the region who are registered at the Chamber of Commerce and obliges these companies to contribute a percentage from their turnover. Based on a distribution key, set by the government, a distinction is made between different types of companies and the amount they contribute. For example, a tourist business directly dependent on tourism pays more than a supermarket. Also the intensity of tourism and recreation in a region determines the weight of this tax. This means that businesses in Tyrol pay a higher tax than those located elsewhere in Austria. In addition, these taxes fund the local "Tourism Association," which puts it into a special development fund for tourism purposes:

Interesting about this Austrian system is that private parties decide for themselves where money is invested in (Director development of a large holiday-homes company, 2018).

With the money from both systems investments are made to innovate and make tourism more sustainable. As opposed to other systems, this one is transparent and fair. The strength of this system is that it has been around for so long. Reintroducing a system like this in this day and age or in the future would probably be very difficult. This means that implementing such a system in the future would require political vision and courage.

\subsection{Seasonal extension reduces vulnerability}

Seasonal extension is not only interesting to increase the total incomes of the enterprises, it is also necessary to recruit and maintain enough personnel and staff of a desired quality. In Ellmau, for instance, the number of tourists in summer has risen by 25 percent since 2013. Crucial for this was the construction of Elmi's Zauberwelt (Elmi's Magical World), a nature play garden for children aged 4 till 12 years built on top of the mountain (see Plate 2). This creates entertainment for families, fits well in the landscape and attracts many people. Also, the restaurants at the top of the mountain and the Bergbahn (the cable car system to get up the mountain) are being used year round.

Another example is the Adventweg (Advent Route) near Katschberg. In the low season before Christmas the village could use an impulse. The Advent Route is an attractive walking tour at a height of 1,750 m, lighted by paraffin lamps. During the tour people can visit renovated old barns where they can listen to storytellers, take part in a small yoga course and so on. This initiative 


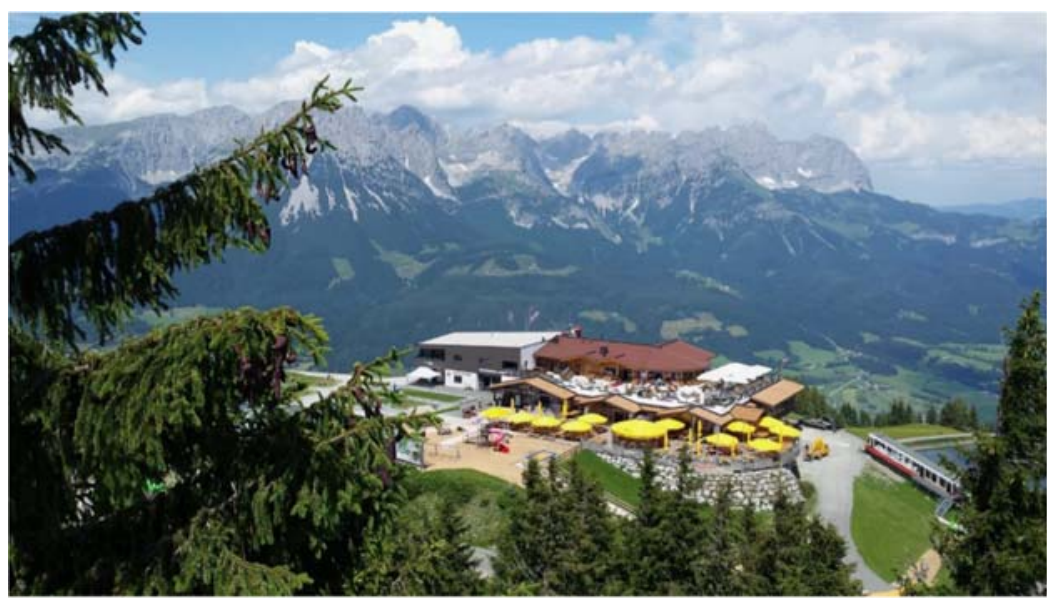

Source: Authors (2018)

received more than 1,200 visitors a day, which is more than was expected. During the summer, the barns are used for instance as small theatres, thus also raising the number of Summer guests. A challenge is to keep the Advent Route an attraction of contemplation whilst so many people are present at the same time:

This is an interesting project. Maybe you should make the Route only accessible for overnight visitors. Then it is even more profitable for the entrepreneurs (Director of a management and exploitation organization of recreation areas, 2018).

The result of all these initiatives is that for instance in Werfenweng at the moment the number of overnight stays in Winter and Summer is almost the same, although people in winter spend way more money per day. Another important benefit is that seasonal extension makes it much easier to offer people jobs year round. This is good for the community as a whole, but it also gives businesses opportunities to invest in their staff by offering them training and courses for example, and thereby raising the quality of hospitality in the region. From a future perspective, these positive effects of seasonal extension make a region less vulnerable to change and increases a region's resilience.

\subsection{Circular economy and sustainable use of resources}

Sustainability, and more precisely sustainable mobility and energy, can be attractors for tourism destinations themselves. This is clearly shown in the case of Werfenweng, the front runner in the Alpine Pearls. People who arrive by train or do not use their car at the destination (and literally hand in their car key at the DMO reception), receive a so-called SaMo card, a card for sustainable mobility, in return (see Plate 3). For $€ 10$, tourists can use this card during their holiday to travel for free with an e-bus, they can make a reservation for an e-car, they will be picked up at the railway station if needed, and they can make use of an e-bike or a Segway and so on. The advantages of the SaMo card have a total value of €350. There is also a SaMo card for locals:

Nice to see that the mayor was able to fully develop an out of the box concept like this (Program manager for the development of a national park, 2018).

Apart from this sustainable mobility concept, Werfenweng only uses (and produces) sustainable energy. Since 2012 the village has its own biomass power station, which uses wood that has grown within a radius of $5 \mathrm{~km}$ around the village. The inhabitants are for 70 percent owner of this company, while the other 30 percent is owned by an energy company. This construction of shared ownership of the plant creates public support for and continuity of the use of sustainable energy. 


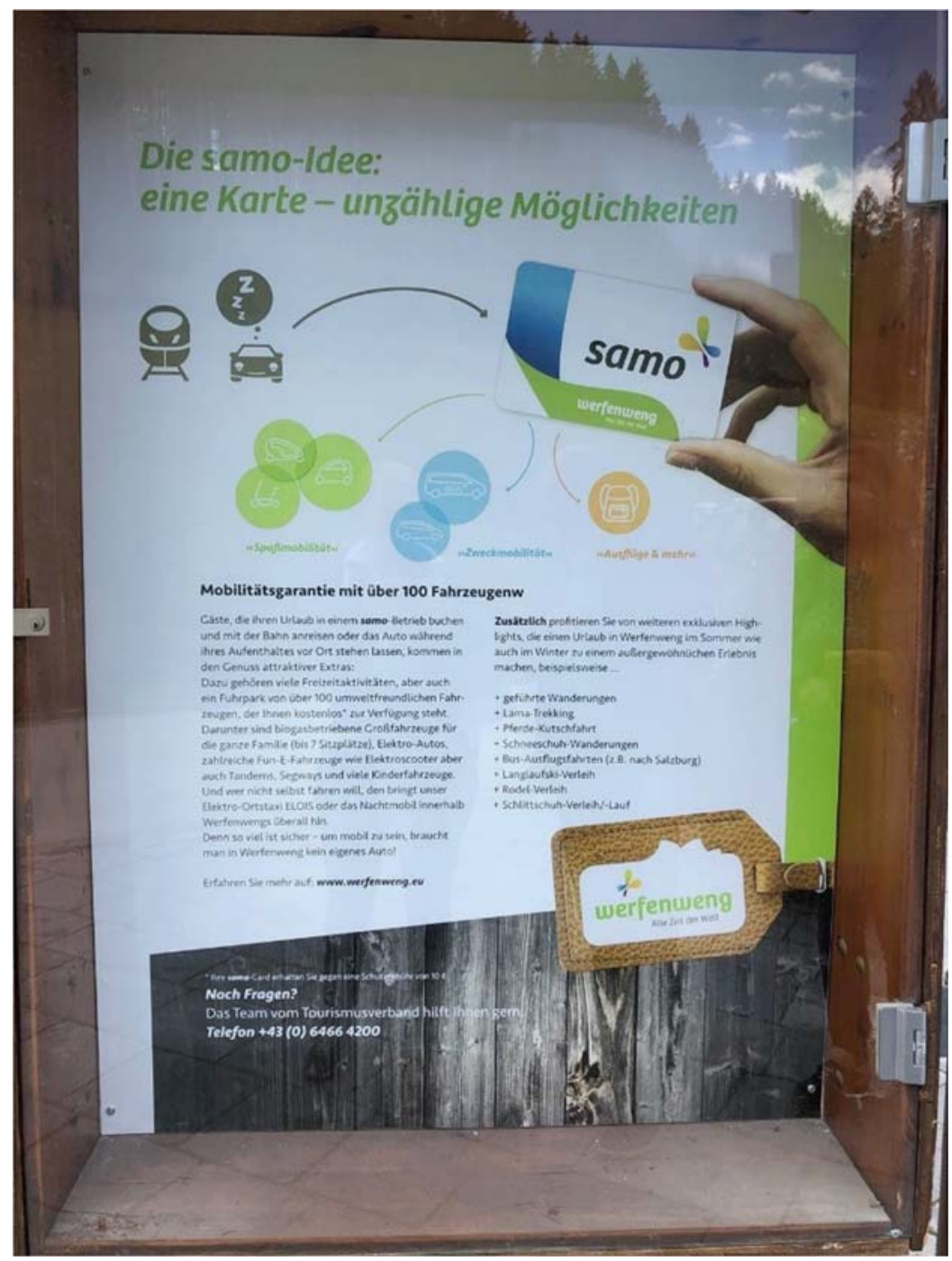

Source: Authors (2018)

About 25 percent of the visitors visit Werfenweng because of their sustainability approach, especially with regard to mobility. However, a critical remark should be made here. At the moment Werfenweng really is the front runner with regard to sustainable mobility. But what will happen when for instance in ten years half of the visitors drive an e-car themselves. What will then be the unique selling point? The lesson here is, that once you are at the front, you should immediately start thinking how to stay in the lead. This means that to keep up with future changes constant innovation is essential:

Now they are leading in sustainable mobility. But what will happen when other and bigger communities speed up? (Director of a large holiday-homes company, 2018).

\section{Conclusion}

The purpose of this viewpoint paper was to provide lessons learned on how innovation can help facilitate sustainable tourism in a region. We argued that for a future proof region, a strategic vision and leadership are needed, close collaboration between stakeholders is crucial and the 
tourism financing system needs to be fair. Also, we found that seasonal extension can reduce vulnerability of a destination and that using resources sustainably and in a circular way can help benefit sustainable tourism. Finally, we observed that when keep up with future changes the job is never done: once a front runner is no guarantee to remain a front runner. Therefore, from a futures perspective this means that continuous innovation is needed. These examples show that for innovation of sustainable tourism, different kinds of innovations are needed which go further than just product innovation.

By means of the lessons in this paper, it contributes to the debate on sustainable tourism, resilience and futures thinking in the following ways. First, the paper contributes to the academic debate on sustainable tourism, by showing practical lessons on how to practically apply this widely discussed concept. These lessons shown can be a great source of inspiration for policy-makers and planners who are working on future policy and plans pertaining sustainable tourism. Nevertheless, we strongly emphasize that we are aware that these observations are context dependent. What works well in Austria, may cause difficulties elsewhere and therefore should not be copied blindly.

Second, our paper contributes to the debate on resilience, because the examples shown, are all about finding balance between different interests and needs of stakeholders that are involved in managing a tourism destination. We found that for the lessons learned mentioned above to be successful, the collaboration between government, industry and scientists should be cherished and intensified were possible.

Third, this paper shows that for a sustainable future of a destination, the time aspect of what it takes to change a future direction should be taken into account. The present situation in Austria is the result of a long tradition of dealing with tourism development. It took a long time to get there and therefore, the development of sustainable forms of tourism in other destinations could take quite some time too. Therefore, it is not only the future changes and challenges that should be taken into account, but also past trajectories can very much determine the direction or directions to which destinations develop.

\section{References}

Alpine Pearls (2018), "Alpine Pearls - nachhaltig reisen in den Alpen", available at: www.alpine-pearls.com (accessed September 19, 2018).

Biggs, D. (2011), "Understanding resilience in a vulnerable industry: the case of reef tourism in Australia", Ecology and Society, Vol. 16 No. 1, pp. 1-18.

Davidson, D. (2010), "The Applicability of the concept of resilience to social systems: some sources of optimism and nagging doubts", Society and Natural Resources, Vol. 23 No. 12, pp. 1135-49.

Espiner, S. and Becken, S. (2014), "Tourist towns on the edge: conceptualising vulnerability and resilience in a protected area tourism system”, Journal of Sustainable Tourism, Vol. 22 No. 4, pp. 37-41.

Hartman, S. (2016), Leisuring Landscapes: On Emergence, Transitions and Adaptation, University of Groningen, Groningen.

Hartman, S. (2018), "Resilient tourism destinations? Governance implications of bringing theories of resilience and adaptive capacity to tourism practice", in Innerhofer, E., Fontanari, M. and Pechlaner, H. (Eds), Destination Resilience: Challenges and Opportunities for Destination Management and Governance, Routledge, Abingdon, pp. 80-90.

Heslinga, J.H. (2018), Synergetic-Tourism Landscape Interactions: Policy, Public Discourse and Partnerships, University of Groningen, Groningen.

Heslinga, J.H., Groote, P.D. and Vanclay, F. (2019), "Examining social-ecological resilience: using content analysis to assess changes in public perceptions of the synergetic interactions between tourism development and landscape protection", in Saarinen, J. and Gill, A.M. (Eds), Resilient Destinations: Governance Strategies of Tourism in the Transition Towards Sustainability, Routledge, Abingdon, pp. 153-70.

Heslinga, J.H., Groote, P.G. and Vanclay, F. (2017), "Using a social-ecological systems perspective to understand tourism and landscape interactions in coastal areas", Journal of Tourism Futures, Vol. 3 No. 1 , pp. 23-38, available at: https://doi.org/10.1108/JTF-10-2015-0047 
Hjalager, A. (1997), "Innovation patterns in sustainable tourism”, Tourism Management, Vol. 18 No. 1, pp. 35-41. Hjalager, A. (2010), "A review of innovation research in tourism", Tourism Management, Vol. 31 No. 1, pp. 1-12.

Lew, A.A. (2014), "Scale, change and resilience in community tourism planning", Tourism Geographies, Vol. 16 No. 1, pp. 14-22.

Luthe, T. and Wyss, R. (2014), "Assessing and planning resilience in tourism", Tourism Management, Vol. 44, October, pp. 161-3.

Moscardo, G. (2008), "Sustainable tourism innovation: challenging basic assumptions", Tourism and Hospitality Research, Vol. 8 No. 1, pp. 4-13, available at: https://doi.org/10.1057/thr.2008.7

STIRR (2018), "Wat is STIRR", available at: www.recreatieenruimte.nl/ (accessed September 19, 2018).

UNWTO (2005), Making Tourism More Sustainable - A Guide for Policy Makers, UNWTO, Madrid, pp. 11-12.

\section{Further reading}

Elmi's Zauberwelt (2018), "Ellmi's world in Ellmau in Tyrol", available at: www.ellmi.at/en/ (accessed September 19, 2018).

Katschberger Adventweg (2018), "Katschberger advent trail”, available at: www.katschberger-adventweg.at/ (accessed September 19, 2018).

\section{Corresponding author}

Jasper Hessel Heslinga can be contacted at: jasper.heslinga@stenden.com

For instructions on how to order reprints of this article, please visit our website: 